\title{
RÜSEN E A TEORIA DA HISTÓRIA COMO CIÊNCIA
}

\section{Aaron Sena Cerqueira Reis*}

Universidade de São Paulo

São Paulo - São Paulo - Brasil

Resenha do livro: RÜSEN, Jörn. Teoria da história: uma teoria da história como ciência. Tradução de Estevão C. de Rezende Martins. Curitiba: Editora UFPR, 2015.

Em Teoria da história: uma teoria da história como ciência, o professor emérito da Universidade de Witten-Herdecke (Alemanha) Jörn Rüsen retoma um conjunto de reflexões que, no Brasil, ficou conhecido a partir da trilogia $R a^{-}$ zão histórica (2001), Reconstrução do passado (2007) e História viva (2007). Na mais recente obra, traduzida para o português por Estevão Chaves de Rezende Martins - professor do Departamento de História da Universidade de Brasília -, o filósofo da história propõe uma revisão de sua teoria, publicada originalmente na década de 1980. Nela, reconhece o pesquisador, não foi possível considerar todo o debate "relevante" e necessário para uma "inovação" de suas ideias. Porém, ao recorrer aos seus próprios trabalhos - aqueles que originaram a trilogia e, também, produções posteriores -, Rüsen nos oferece uma síntese do que há de mais importante e atual em sua obra.

\footnotetext{
* Doutorando na Faculdade de Educação da Universidade de São Paulo e bolsista da Coordenação de
} Aperfeiçoamento de Pessoal de Nível Superior - Capes. E-mail: aaron_sena@hotmail.com. 
Desde que os principais trabalhos do historiador alemão foram traduzidos para o português, suas ideias acerca da teoria da história têm influenciado pesquisas no âmbito de diferentes programas de graduação e pós-graduação em História e Educação. Nesse sentido, estudos como os de Barom ${ }^{1}$ e Oliveira, ${ }^{2}$ que analisaram as contribuições do pensamento rüseniano para o campo da história e seu ensino no Brasil, observaram um significativo crescimento no número de produções acadêmicas baseadas nessas reflexões.

A relevância dos trabalhos de Rüsen consiste na articulação entre o saber histórico acadêmico e o saber histórico escolar com base na realidade da pesquisa científica. Ao apresentar a obra ora resenhada, Estevão Chaves de Rezende Martins, Maria Auxiliadora Moreira dos Santos Schmidt e Arthur Alfaix Assis ponderam que a apropriação das ideias desse historiador para a área do ensino de História no Brasil representou "uma mudança radical nos fundamentos da aprendizagem histórica" (p. 16), favorecendo o desenvolvimento de novas questões de estudos a partir da valorização da consciência histórica de estudantes e professores. Em outras palavras, a utilização do pensamento rüseniano contribui com a produção de pesquisas cujo foco recai não apenas sobre os processos de aquisição do conhecimento histórico, mas, também, na forma como estes saberes se relacionam com a vida prática de sujeitos em situação escolar ou não.

Considerando que o pensamento original do teórico estava alinhado à virada sociológica dos anos 1960 e 1970, Rüsen enfrentou o desafio de, por um lado, não recusar radicalmente a tradição historicista que o influenciou, articulando, por outro lado, as "concepções analíticas pós-historicistas da história social com os modos neo-hermenêuticos de pensar" (p. 26). Ou seja, para o mesmo, não obstante os apelos transdisciplinares que "desacreditaram as pretensões de racionalidade do conhecimento", o historiador não deve eximir os resultados de sua pesquisa da "pretensão controlável de validade" (p. 27). Tal caminho pode ser trilhado valorizando-se a "condição humana", capaz de intermediar diferentes formas de pensar - sejam elas relacionadas à tradição científica ocidental ou não - e também pela valorização da história como ciência, cuja teoria pode legitimar o processo de

\footnotetext{
BAROM, Wilian Carlos Cipriani. A teoria da história de Jörn Rüsen no Brasil e seus principais comentadores. Revista História Hoje, vol. 4, no 8, 2015, p. 223-246. Disponível em: <https://rhhj. anpuh.org/RHHJ/article/view/200/147>. Acesso em: 01/07/2016.

2 OLIVEIRA, Carla Karinne Santana. "O livro didático ideal" em questão: estudo da teoria da formação histórica de Jörn Rüsen em livros didáticos de História (PNLD-2008). Dissertação de mestrado, Programa de Pós-Graduação em História, Universidade Federal da Paraíba, 2012.
} 
constituição de história com sentido para a vida. Estas questões constituem o eixo norteador da obra.

Inicialmente, Rüsen explica o que entende por teoria da história. Apesar de aparentemente simples - "a teoria da história é a teoria da história como ciência" (p. 31) - a reflexão se torna um pouco mais complexa quando se considera a incompatibilidade do modelo empírico da história com o modelo das ciências exatas, por exemplo. Por este motivo, refletir sobre a teoria da história é, para o autor, refletir sobre o processo de interpretação da história em suas dimensões disciplinar (como ciência especializada), interdisciplinar (na relação com outras disciplinas científicas) ou transdisciplinar (na relação do seu saber específico com a vida prática).

Atrelado à necessidade humana de interpretar o tempo, o pensamento histórico fundamenta-se, na teoria de Rüsen, em um conjunto de operações (experiência, interpretação, orientação e motivações) que precisam ser conectadas e inseridas em uma lógica narrativa de apresentação para estruturar o pensamento e conferir sentido aos eventos históricos. Assim, o autor define a história como "uma conexão temporal, plena de eventos, entre passado e presente (com uma projeção para o futuro), que, por sua representação sob a forma de narrativa, possui sentido e significado para a orientação da vida prática atual" (p. 52). No entanto, ressalta, esta narrativa se diferencia de outros tipos, pois se refere a "acontecimentos reais do passado" (p. 54) e possui uma ética interna baseada em um "superávit" de intenções e buscas de sentido expressas pelo homem.

Na teoria rüseniana, o elemento que faz da história ciência é o método. Contudo, o fundamento antropológico deste tipo de pesquisa confere aos resultados obtidos uma "verdade plausível", que só faz sentido "quando é útil à vida" (p. 63, grifo do autor). Portanto, os critérios de verdade do pensamento histórico são definidos de maneira "intersubjetiva", o que pressupõe "a capacidade de reconhecer a própria diferença, mediante o outro" (p. 69, grifo do autor). Isso corrobora a ideia de que a validade da história como ciência não se restringe à relatividade específica de uma cultura.

Essas definições gerais, que mostram como a história se relaciona com as diferentes práticas humanas, destacam a importância de compreender seu processo de operação concreta, ou seja, como a história é produzida. Assim, Rüsen elabora "um esquema dos procedimentos intelectuais do pensamento histórico", capaz de distinguir "os critérios decisivos do conhecimento" e evidenciar "suas diferenças e sua interdependência" (p. 72). Este é o mecanismo da sua "matriz disciplinar", inspirada no paradigma de ciência de Thomas 
Khun, por meio da qual o historiador se preocupa em "esclarecer, analiticamente, a particularidade estrutural da ciência da história" (p. 72).

Nesta matriz disciplinar são evidenciados: fatores, que mostram a indissociabilidade do pensamento histórico científico e da cultura histórica; práticas, que denotam a estrutura comunicativa do pensamento histórico; e diferentes níveis de constituição de sentido, os quais apontam para a nossa falta de domínio sobre os elementos prévios que conferem significado ao passado. Estas ideias são articuladas às especificidades operacionais do conhecimento histórico e compõem um sistema de categorias, teorias e conceitos, conferindo-lhe status de cientificidade. A importância deste sistema, que na teoria rüseniana é a própria "história", nos obriga a perscrutá-lo.

As categorias demarcam o pensamento histórico nas dimensões empírica, formal e funcional, oferecendo representações de experiências humanas a partir das diferentes formas do saber histórico, viabilizando uma orientação para a vida prática. As teorias estabelecem uma ordem dentro do campo da experiência evidenciada, ou seja, dentro de um determinado contexto temporal e, por isso, definem-se como "enredos" que atribuem "sentido" às "narrativas históricas" quando "explicitadas conceitualmente como tais e quando operáveis metodicamente" (p. 154). Finalmente, os conceitos estabelecem "a relação empírica" entre "os fenômenos do passado e a relação significante desse passado com o presente" (p. 157). Tais elementos expressam uma função cognitiva que "transpõe a interpretação do passado para a vivacidade de sua apresentação" (p. 159).

O sistema pelo qual opera o conhecimento histórico confere ao seu pensamento "um caráter racional". Apesar de contrapor-se ao modelo científico baseado em regularidades de leis, o pensamento histórico adquire sua "força explicativa", sobretudo, na narratividade da teoria da história. Isso não descarta a possibilidade de apropriação de modelos explicativos nomológicos. Entretanto, tal opção depende do tipo de pergunta a que o historiador pretende responder.

Sem negar a semelhança com a sistemática historicista de Droysen, o método histórico de Rüsen é definido como um "caminho" que regula o pensamento histórico por meio de um procedimento cognitivo cujas estratégias são constituídas pela heurística (seleção das fontes), crítica (avaliação das fontes) e interpretação (apresentação do saber produzido). Dessas estratégias, o historiador nos leva a crer que a interpretação é a operação mais "complexa", tendo em vista as necessidades de "teorizar" sobre os contextos históricos e "historicizar" os fatos obtidos pela crítica (p. 186). A interpretação "conecta os fatos do passado" por meio de uma "intersubjetividade controlá- 
vel" que o investe de uma "função explicativa", produzindo, assim, o "saber histórico" (p. 184-185), apresentado em forma narrativa. Contudo, adverte o autor, é preciso diferenciar esta apresentação do próprio conhecimento: ela é, simplesmente, um "modo de lidar com os resultados da pesquisa" (p. 171).

Diretamente relacionada à apresentação histórica (tópica), a interpretação é analisada a partir das especificidades narrativas que ordenam o campo historiográfico. Nele, seu esquema de ordenação é definido por uma tipologia que "resume a multiplicidade das apresentações historiográficas em algumas formas básicas" (p. 201). Consideradas "tipos ideais", estas narrativas possuem elementos argumentativos que evidenciam o caráter científico da história, ainda que atribuam diferentes sentidos à experiência desta natureza. Por conseguinte, a história pode se basear nos modelos: tradicional, cujo sentido é "uno e duradouro"; exemplar, cujo sentido pode ser sintetizado na máxima "história mestra da vida"; crítico, cujo sentido é a negação de orientações prévias; e genético, cujo sentido é adquirido na mudança, permitindo que o passado seja conectado a diferentes formas de viver.

Por outro lado, Rüsen não descarta os fatores subjetivos que fundamentam a cultura histórica e, consequentemente, influenciam na produção historiográfica, bem como na construção da consciência histórica. Por meio dos aspectos cognitivo, estético, político, moral e religioso é possível satisfazer carências de orientação da vida prática, em que o passado "presentificado" pode ser visto como um produto de embates entre memórias pessoal e coletiva. Logo, o historiador percebe uma "rede complexa de relações", cuja marca é a "contraposição e interdependência" de sentidos que podem conduzir a uma "consciência falsa da realidade" (p. 235-241).

Todavia, sabendo que a ciência da história é responsável pelo controle de plausibilidade do saber que produz, o historiador sugere atenção a um tipo de ideologia baseado nos critérios da razão prática, ou critérios humanísticos, o qual "se constitui a partir da estrutura formal de uma interpretação do mundo abrangente, usualmente articulada com a pretensão de cientificidade" (p. 242). Somente assim, afirma o pensador, é possível relacionar a matriz disciplinar do conhecimento histórico não só às carências de orientação, mas, também, a outros processos de aplicação prática do conhecimento como o ensino e a aprendizagem histórica.

Os processos de ensino e aprendizagem histórica constituem o objeto da didática da história, uma disciplina especializada que, apesar de possuir métodos de pesquisa próprios, depende dos fundamentos básicos de sentido oferecidos pela teoria da história. Com esta articulação, a aprendizagem favorece a aquisição de competências que habilitam os indivíduos "a narrar as histórias 
de que têm necessidade para dar conta da dimensão temporal de sua própria vida" (p. 252). Nesse processo, os níveis de reflexão sobre os saberes adquiridos podem revelar uma "lógica evolutiva", baseada na tipologia que denota as diferentes formas pelas quais o sujeito atribui sentido à sua experiência.

Conforme Rüsen, o pensamento histórico resultante da aprendizagem contribui para a formação da identidade, construída a partir de uma "diversidade de identificações" em perspectiva "temporal" (p. 261-263). Porém, ao destacar seu caráter "eminentemente político", o filósofo reconhece que tal processo pode conduzir o indivíduo a um pensamento etnocêntrico, onde seu "eu" se vê como centro do mundo, aumentando, assim, as tensões e conflitos entre diferentes culturas. Considerando este problema, Rüsen prevê a valorização da qualidade humana como elemento de superação, favorecendo a construção de uma teleologia orientada para o futuro, através de uma perspectiva policêntrica. Com esta "hermenêutica humanizante", inspirada no pensamento kantiano, o conhecimento histórico torna as diversas formas de vida inteligíveis e exige, para isso, um "reconhecimento mútuo da diferença cultural" (p. 273).

O desfecho da obra é marcado por uma retomada da tese central, na qual o historiador ressalta que a articulação do passado ao futuro com o objetivo de atender às carências de orientação do presente devem ser sustentadas pela "determinação constante de sentido" (p. 275). Este elemento - o sentido - deve ser compreensível, significativo e capaz de garantir a orientação na vida prática, não obstante sua vinculação a uma pluralidade de culturas históricas. É justamente esta característica que liga o sentido histórico ao "contrassenso", isto é, uma "significância precária" que estimula a busca de significados históricos.

Finalmente, Rüsen pondera que, não obstante a história como ciência propiciar a constituição de sentidos mediante o pensamento metódico, a razão humana não pode ser restringida a esse tipo de pensamento, pois "há inúmeras outras carências de orientação, muito fortes, que não podem ser satisfeitas pelos resultados cognitivos do conhecimento histórico" (p. 285). Isso não quer dizer que o pensamento histórico deva ser menosprezado. Ao contrário, o reconhecimento dos limites que a história como ciência impõe ao seu tipo de pensamento nos permite articular o "contrassenso da experiência de vida" à confiança depositada nos "elementos prévios de sentido" (p. 287).

Diante do exposto, consideramos inegável o valor da produção intelectual de Rüsen e, especificamente, da obra analisada. Embora não apresente elementos diferentes daqueles já conhecidos pelo público brasileiro, tanto pela referida trilogia, quanto pelos diversos artigos e livros já publicados 
no país, a exemplo de obras do próprio autor ${ }^{3}$ e organizadas por outros pesquisadores, como Schmidt, Barca e Martins ${ }^{4}$ e Schmidt e Martins, ${ }^{5}$ esta despretensiosa Teoria da história nos oferece os principais caminhos para compreendermos o pensamento de um estudioso que tem contribuído com a história e o ensino de história.

Ao reunir e articular os mais importantes conceitos construídos ao longo de sua trajetória profissional - como consciência, cultura, narrativa e aprendizagem históricas, teoria e didática da história - Rüsen nos possibilita a compreensão de diferentes formas de atribuição de sentido à experiência humana ou, mesmo, a percepção das dificuldades de atribuição de sentido, exemplificada em ideias como "crise", "trauma" e "luto". Seu pensamento historicista, relacionado a uma hermenêutica cultural que valoriza a condição humana, nos permite, enfim, refletir sobre uma teoria da história inclusiva. Por isso, a leitura desta Teoria da história como ciência se torna imprescindível aos pesquisadores e pesquisadoras interessados em fomentar a construção de sentidos para seus objetos de estudo e, ainda, aos professores e professoras que necessitam compreender e contribuir com o desenvolvimento da consciência histórica de seus estudantes.

\section{Referências bibliográficas}

BAROM, Wilian Carlos Cipriani. A teoria da história de Jörn Rüsen no Brasil e seus principais comentadores. Revista História Hoje, vol. 4, nº 8, 2015, p. 223246. Disponível em: < https://rhhj.anpuh.org/RHHJ/article/view/200/147>. Acesso em: 01/07/2016.

OLIVEIRA, Carla Karinne Santana. "O livro didático ideal" em questão: estudo da teoria da formação histórica de Jörn Rüsen em livros didáticos de história (PNLD-2008). Dissertação de mestrado, Programa de Pós-Graduação em História, Universidade Federal da Paraíba, 2012.

RÜSEN, Jörn. Aprendizagem histórica: fundamentos e paradigmas. Tradução de Peter Rautmann, Caio Pereira, Daniel Martineschen e Sibele Paulino. Curitiba: W. A. Editores, 2012.

\footnotetext{
3 RÜSEN, Jörn. Aprendizagem histórica: fundamentos e paradigmas. Tradução de Peter Rautmann, Caio Pereira, Daniel Martineschen e Sibele Paulino. Curitiba: W. A. Editores, 2012; RÜSEN, Jörn. Cultura faz sentido: orientações entre o ontem e o amanhã. Tradução de Nélio Schneider. Petrópolis: Vozes, 2014.

4 SCHMIDT, Maria Auxiliadora; BARCA, Isabel; MARTINS, Estevão de Rezende (org.). Jörn Rüsen e o ensino de história. Curitiba: Editora UFPR, 2010.

${ }_{5}^{5}$ SCHMIDT, Maria Auxiliadora \& MARTINS, Estevão de Rezende (org.). Jörn Rüsen: contribuições para uma teoria da didática da história. Curitiba: W. A. Editores, 2016.
} 
Cultura faz sentido: orientações entre o ontem e o amanhã. Tradução de Nélio Schneider. Petrópolis: Vozes, 2014.

. História viva: formas e funções do conhecimento histórico. Tradução de Estevão de Rezende Martins. Brasília: Editora da Universidade de Brasília, 2007.

. Razão histórica: os fundamentos da ciência histórica. Tradução de Estevão de Rezende Martins. Brasília: Editora da Universidade de Brasília, 2001.

Reconstrução do passado: os princípios da pesquisa histórica. Tradução de Asta-Rose Alcaide. Brasília: Editora da Universidade de Brasília, 2007.

SCHMIDT, Maria Auxiliadora; BARCA, Isabel; MARTINS, Estevão de Rezende (org.). Jörn Rüsen e o ensino de história. Curitiba: Editora UFPR, 2010.

SCHMIDT, Maria Auxiliadora \& MARTINS, Estevão de Rezende (org.). Jörn Rüsen: contribuições para uma teoria da didática da história. Curitiba: W. A. Editores, 2016. 